Journal of Computer Science 5 (3): 199-206, 2009

ISSN 1549-3636

(C) 2009 Science Publications

\title{
Performance Enhancement of Underwater Target Tracking by Fusing Data of Array of Global Positioning System Sonobuoys
}

\author{
${ }^{1}$ Ahmed El-Shafie, ${ }^{2}$ Abdallah Osman, ${ }^{2}$ Aboelmagd Noureldin and ${ }^{3}$ Aini Hussain \\ ${ }^{1}$ Department of Civil and Structural Engineering, University Kebangsaan Malaysia, Malaysia \\ ${ }^{2}$ Department of Electrical and Computer Engineering, Royal Military College, Kingston, ON Canada \\ ${ }^{3}$ Department of Electronics System Engineering, University Kebangsaan Malaysia, Malaysia
}

\begin{abstract}
Problem statement: An accurate knowledge of geographic positions of sonobuoys is critical for the conduct of antisubmarine warfare operations and detected target localization. Deployed from an airborne platform or a surface vessel, arrays of sonobuoys could be used to efficiently track and localize submarines. Lastly, some sonobuoys were being equipped with GPS for improving system accuracy and potentially allowing networked Sonobuoy positioning. However, the computation of the range using the propagation loss profile and the data of one sonobuoy usually leads to inaccurate target localization due to several effects and uncertainties. It was, alternatively, reported that if the target is within the detection rage of two or more sonobuoys, greatly improved target localization can be achieved. Approach: Aim of this research was to investigate the feasibility of fusing data from a distributed field of GPS sonobuoys to create an Artificial Intelligence (AI) based model for the error of the range computation in case of the target being detected by only one sonobuoy. Proposed module was designed utilizing Adaptive Neuron-Fuzzy Inference Systems (ANFIS) to estimate the range error associated with the computation using the propagation loss profile when the target is within the detection range of only one sonobuoy. The architecture of the proposed ANFIS system had two unique features. First was the real-time cross-validation applied during the update (training) procedure of the ANFIS-based module while the target was detected by two sonobuoys and the range was computed. Second feature was the use of non-overlapping and moving window for the real-time implementation of the ANFIS-based data fusion module. Results: Performance of the proposed system was examined with simulation data considering different scenarios for both the array of GPS sonobuoys and the target. Results showed that the corrected positioning by one sonobuoy is completely following the positioning by two sonobuoys over the entire experiment with the error in between evaluated to have RMSE value of $0.004 \mathrm{Nm}$ and 0.008 for both scenarios. Conclusion: These results revealed that with aided from the proposed ANFIS model; significant enhancements to the underwater target tracking accuracy in cases of single sonobuoy detection could be achieved and thus maintaining consistent levels of accuracy over the whole tracking mission.
\end{abstract}

Key words: Tracking, data fusion, GPS sonobuoys, neuron-fuzzy systems

\section{INTRODUCTION}

The problem of target detection and tracking in the ocean environment has attracted considerable attention in the past two decades due to its importance in military, oceanographic and fisheries applications ${ }^{[1]}$. Underwater target localization is mainly based on the fact that ships and submarines, like any other vehicles, require a large amount of energy for propulsion and for powering mechanical and electronic equipment. Some of the energy radiates outwards as acoustic energy in the form of both broadband and narrowband signal $^{[2]}$.

Sonobuoys: A sonobuoy is a free floating and disposable sensor system. The sonobuoy uses acoustic sensors in the water column connected by wire to a floating part on the surface of the ocean to listen to submarine radiated noise or sonar echoes. An electromagnetic transmitter in the floating part relays the acoustic signals back to an airplane or other receiving platform for further processing. If the

Corresponding Author: Ahmed El-Shafie, Department of Civil and Structural Engineering, University Kebangsaan Malaysia, Malaysia 
Sonobuoy contains a magnetic compass and a beamformer to localize the acoustic signal in azimuth, then the submarine's bearing can be determined relative to the sonobuoy's location.

A sonobuoy can be deployed from an airborne platform, a rotary-wing aircraft, or a surface vessel. Two general types of sonobuoys are used for target tracking; passive and active sonobuoys. Passive sonobuoys quietly listen to the acoustic signal from a target. Active sonobuoys, on the other hand, emit a sound pulse (ping) to generate an echo that bounces back from the target. In this study we offer a data fusion module for an array of passive sonobuoys.

GPS sonobuoys: An accurate knowledge of geographic positions of deployed sonobuoys is critical for the conduct of coordinated antisubmarine warfare (ASW) operations, high-altitude ASW and detected target localization. This leads to introduction of Global Positioning Systems (GPS) to the sonobuoys. Previously, the operation depended on a monitoring aircraft to perform a Mark On Top (MOT), which is time consuming, provides insufficient accuracy, increases the vulnerability of the aircraft and generally provides a tactical rather than a geographic position for the target. Sonobuoys equipped with GPS for positioning are known as GPS sonobuoys ${ }^{[3]}$.

Target localization: At the receiver unit of the Sonobuoy, an omnidirectional element measures incident acoustic energy from any direction, which can be used according to the chart in Fig. 1 to determine the approximate range of the target. The graph in Fig. 1 shows the propagation loss (in $\mathrm{dB}$ ) as a function of range from the source for specific frequency and water environment such as temperature and salinity. The Figure Of Merit (FOM) is obtained by subtracting ambient noise from the signal level (received by the omnidirectional sensor of the sonobuoy). When the value of the FOM is projected to the propagation loss profile of Fig. 1, the corresponding range of the target can be computed.

The bearing of the target (measured from the North) is determined using a cruciform shaped assembly that is composed of four ceramic discs, the orientation of which results in a beam pattern for each pair of discs similar to a dipole. These beam patterns are referred to as the sine and cosine lobes and are referenced to Magnetic North ${ }^{[1,2]}$.

The computation of the range using the propagation loss profile and the data of one sonobuoy usually leads to inaccurate target localization due to several effects and uncertainties. It was, alternatively, reported that if the target is within the detection rage of two or more sonobuoys, greatly improved target localization can be achieved. Figure 2 and Eq. 1 demonstrates how the target can be accurately localized using the bearing information (which can be accurately determined using some signal processing and spectral analysis techniques ${ }^{[1,2]}$ ) and the known distance between two sonobuoys, which can be accurately determined given the sonobuoys are equipped with GPS $^{[4]}$ :

$\mathrm{d}_{1}=\frac{\mathrm{d} \sin \left(\theta_{2}-\alpha\right)}{\sin \left(\theta_{1}-\theta_{2}\right)}$

$d_{2}=d \cos \left(\theta_{2}-\alpha\right)+d_{1} \cos \left(\theta_{1}-\theta_{2}\right)$

Where:

$\mathrm{d}_{1}$ and $\mathrm{d}_{2}=$ The range of the target with respect to sonobuoy SB1 and sonobuoy SB2, respectively

$\theta_{1}$ and $\theta_{2}=$ The bearing of the target with respect to SB1 and SB2, respectively

$\alpha=$ The angle from the true north to the line between the two sonobuoys

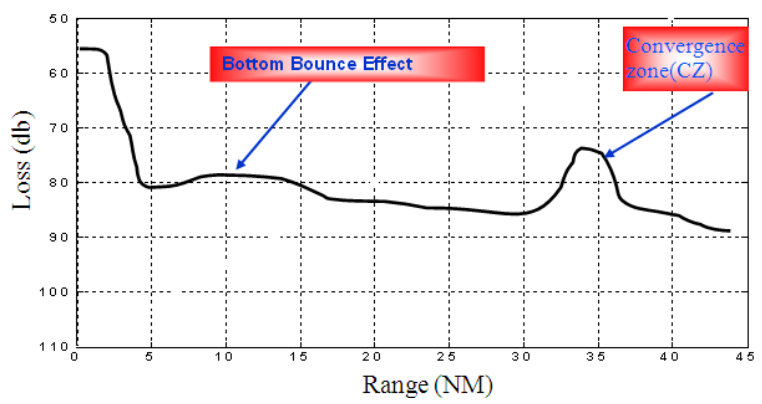

Fig. 1: The propagation loss profile

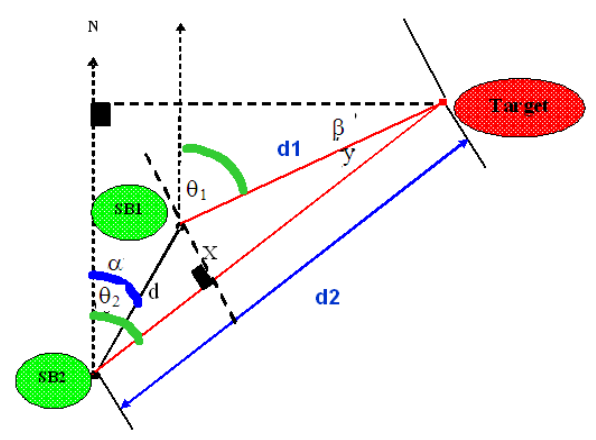

Fig. 2: Target localization using two sonobuoys

Problem statement: In real underwater target tracking procedures, it is not common for a target to be located 
within the detection rage of two or more sonobuoys. Thus the localization accuracy continues to be relatively poor when the target is within the detection range of a single sonobuoy. This research is investigating a model for the range error associated with the computation when using a single sonobuoy and with tuning the model when the target comes into the detection range of two or more sonobuoys.

Objectives: The main aim of this research is to create an Artificial Intelligence (AI) based model for the error of the range computation in case of the target being detected by only one sonobuoy. The neuro-fuzzy models will be employed in this study combining the capabilities of fuzzy systems in dealing with high levels of uncertainty in the input domain and the advantages of neural computation.

Neuro-fuzzy systems: Fuzzy systems have been widely accepted as general approximators and were successfully implemented to learn relationships ${ }^{[5]}$. They will be adopted in this study to determine the error in the computation of target range when it is detected by only one GPS Sonobuoy. While there are various techniques to implement approximate fuzzy reasoning, most of these techniques are based upon inductive learning from examples by building fuzzy rules derived from input/output data tuples. Adaptive Neuro-Fuzzy Inference System (ANFIS) was proposed as the tool for real time implementation. While ANFIS has capabilities similar to other fuzzy systems in considering uncertainties in the input domains, it has the advantage over other models for being based on neural computation (combines backpropagation and least mean square optimization algorithms). ANFIS architecture is based on the original Tagaki-SugenoKang (TSK) fuzzy inference system ${ }^{[6]}$. When an adequate number of data tuples exist, learning can be achieved by tuning the membership functions using gradient descent method to determine the premise parameters, along with applying the least mean square method to modify the consequent parameters so that the model output matches the system output with a minimum root mean square error.

The R- $\delta \mathrm{R}$ ANFIS-based module was designed to work in real-time to fuse the range computation made using one sonobuoy (R1S) with that of two sonobuoys (R2S), estimates the range error $\delta R_{1 s}$ and enhances the target tracking operations. Two inputs (R1S and time) and one output $\left(\delta R_{1 s}\right)$ were used in the $R-\delta R$ module.
Schematic representation of the proposed ANFIS module for data fusion is shown in Fig. 3.

The number and shape of membership function are predefined. However, the original spread and overlap of the membership functions is defined by using fuzzy clustering algorithm. The membership function parameters are then tuned during the learning process. The fuzzy Norm operator ( $\Pi$ ) (minimum or product) is operated at the second layer of ANFIS and a normalized firing strength $\overline{\mathrm{W}}_{\mathrm{i}}$ is computed in the third layer for each (i) consequent ${ }^{[5,6]}$. The system output (i.e., $\left(\delta R_{1 s}\right)$ is computed on the basis of TSK fuzzy system as follows:

if $\mathrm{x}$ is $\mathrm{A}_{1}$ and $\mathrm{y}$ is $\mathrm{B}_{1}$, then $\mathrm{f}_{1}=\mathrm{p}_{1} \mathrm{x}+\mathrm{q}_{1} \mathrm{y}+\mathrm{r}_{1}$

if $\mathrm{x}$ is $\mathrm{A}_{2}$ and $\mathrm{y}$ is $\mathrm{B}_{2}$, then $\mathrm{f}_{2}=\mathrm{p}_{2} \mathrm{x}+\mathrm{q}_{2} \mathrm{y}+\mathrm{r}_{2}$

$\delta \mathrm{R}=\sum \mathrm{w}_{\mathrm{i}} \mathrm{f}_{\mathrm{i}}$

(5)

where, the linear parameter $p_{i}, q_{i}$ and $r_{i}$ are the consequent parameters determined by the fuzzy system to relate the input fuzzy sets to the output fuzzy sets. The output $\left(\delta R_{1 s}\right)$ in the fifth layer is the sum of the weighted outputs of all the fuzzy rules as in Eq. 2. While training ANFIS, the consequent parameters $\left\{\mathrm{p}_{\mathrm{i}}, \mathrm{q}_{\mathrm{i}}, \mathrm{r}_{\mathrm{i}}\right\}$, are determined using means of least squares. If the predicted mean square error does not meet the required error, ANFIS module tunes the parameters describing the membership functions for each input parameter until the training target is achieved.

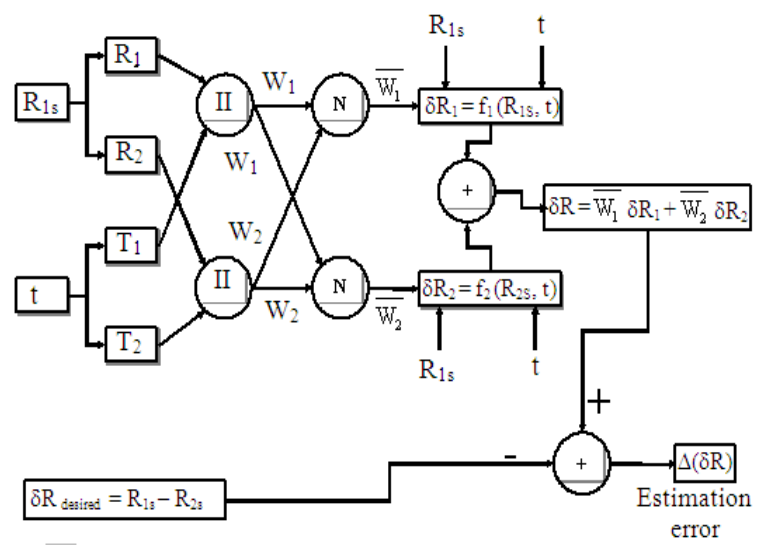

Fig. 3: ANFIS architecture for Sonobuoys range error modeling 


\section{MATERIALS AND METHODS}

Model structure: Our method is based on the fact that target localization using two or more sonobuoys can provide much better accuracy than the conventional method relying on only one sonobuoy. The ANFIS module will be tuned (updated or trained) if the target is within the detection range of at least 2 sonobuoys as shown on Fig. 4a. The ANFIS module will be switched into prediction mode (Fig. 4b) when the target is within the detection range of only one sonobuoy. As shown in Fig. $4 a$, the range $\left(\mathrm{R}_{1 \mathrm{~S}}\right)$ and time $(\mathrm{t})$ are the inputs to the ANFIS module while the range error $\left(\delta R_{1 s}\right)$ is the module output. The error estimated by the ANFIS module $\left(\delta R_{1 s}\right)$ is then compared to the error between $R_{1 S}$ and $R_{2 S}\left(\delta R_{1 s \mid 2 s}\right)$. The difference between $\delta R_{1 s}$ and $\delta R_{1 s \mid 2 s}$ is the estimation error $(\Delta(\delta R))$ of the ANFIS module. In order to minimize this error, the ANFIS module is trained to update the rule-base parameters that describe the fuzzy system premises and consequences, such that the Root Mean Square Estimation Error (RMSE) is minimized.

On the other hand, when the target becomes in the detection range of only one sonobuoy, the system is switched to the prediction mode where the ANFIS module is used to predict the error $\delta \mathrm{R}_{1 \mathrm{~s}}$ using the latest ANFIS parameters obtained while the target is detected by two sonobuoys as shown in Fig. $4 \mathrm{~b}$. The error is then removed from the corresponding range computation $R_{1 S}$ to get the corrected range error.

The system architecture of the proposed module is designed to estimate the range error associated with the computation using the propagation loss profile when the target is within the detection range of only one sonobuoy. The proposed system has two unique features. The first is the real-time cross-validation applied during the update (training) procedure of the ANFIS-based module while the target is detected by two sonobuoys and the range is computed as per Eq. 1 . The second feature is the use of non-overlapping and moving window for the real-time implementation of the ANFIS-based data fusion module. The non-overlapping moving window does not consider any redundancy in the information acquired from the sonobuoys. In other words, the data window moves in real-time with steps equal to the window size.

Cross validation: Several methods for implementing the cross-validation theory were proposed in the literature ${ }^{[7]}$, however, the essence of all these methods is similar. We start by dividing the whole data into $g$ equal-sized groups and conduct $g$ separate operations.

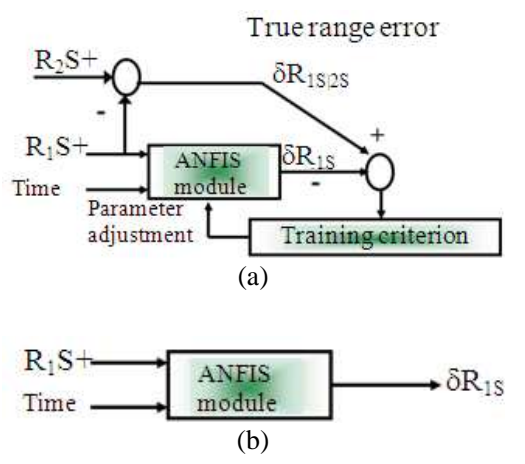

Fig. 4: Update and prediction mode of operations for range fusion of array of GPS sonobuoys (a): Update mode (b): Prediction mode

Each group is omitted in turn from the data, the model is fitted to the remaining (g-1) groups and the predictions are estimated for the omitted group.

It is worth noting that the efficiency of any crossvalidation method is classified into two categories: accuracy and stability. While accuracy of the method is usually represented by the error of the algorithm on the training set, instability of the method represents its sensitivity to noise in the input data. Due to its simplicity and suitability for real time implementation, the hold out cross validation method is adopted in this study. The data set is partitioned into two sets, called the training set and the testing set without any particular choice of the partition. The function approximator is trained to fit a function using the training set only. Then the function approximate is used to predict the output values for the data in the testing set. While this method has the advantage of not being computationally expensive, it might yield relatively high variance ${ }^{[7]}$.

During the update procedure, we may experience two cases. When maximizing the accuracy (minimizing RMSE on the training set) was tried, it was found that the system's stability tends to decrease (relatively higher RMSE value during cross validation). On the other hand, when trying to maximize the system's stability, the accuracy tends to decrease (relatively higher RMSE value during training). If the goal is to minimize the cross-validation error, then a balance between the conflicting demands of accuracy and stability must be reached. In this study, for a given set of ANFIS parameters, this balance was obtained by minimizing the RMSE on the training set to $10-4 \mathrm{~m}$ and achieving the best possible stability, which was obtained by making the length of the cross-validation part of the data equal to $1 / 5$ of the window size. 


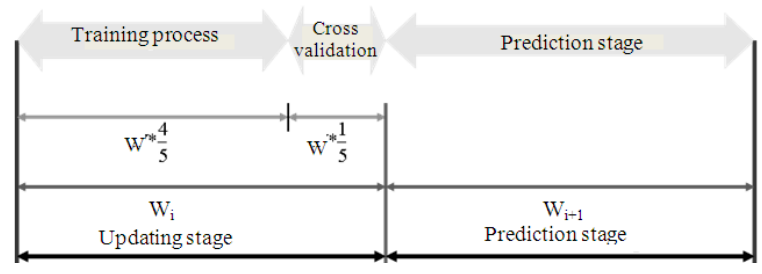

Fig. 5: Time line index for the model update and prediction sequences

It should be noted that the updating stage is divided into two consequent parts namely, training and crossvalidation sessions. Figure 5 shows the time line index for the sequences of the two stages.

As shown in Fig. 5 that during the update stage (training), a hold-out cross-validation algorithm is used to ensure that the ANFIS-based module has appropriately captured the system dynamics. The choice of the hold-out method is attributed to its relative stability and low computational time requirements which is a major challenge in real-time applications. The system automation based on training and crossvalidation during the updating stage. A major challenge in applying the cross-validation approach is the need to select the length of the testing data set $(\mathrm{N})$ utilized. It is important for this selection to be representative for features of the error signal.

Different lengths of the cross-validation data set ranging from one tenth to one third of the window size were examined. We determined that choosing one third of the window size lead to short data set for the training process that may cause difficulty to reach the error goal. While choosing one tenth of window size lead to weakness in detecting the features of the expected data set in prediction stage since it leads to relatively short data set for the cross validation procedure. Therefore, it was decided to select the length of data set for crossvalidation utilized in our study to be one-fifth of the window size Fig. 5.

\section{RESULTS}

In order to examine the performance of the proposed method and the ANFIS module, we simulated two target tracking scenarios assuming a submarine moving at a speed of $5 \mathrm{~m} \mathrm{sec}^{-1}$. The first scenario assumed the sonobuoys were deployed as $4 \times 4$ array (Fig. 6) while the second assumes that the sonobuoys were deployed as $4 \times 2$ array (Fig. 7). For each scenario we considered two cases. The first case assumed the distance between any two sonobuoys to be equal to the sonobuoy detection range while the second case considered a distance of 1.2 the detection range.

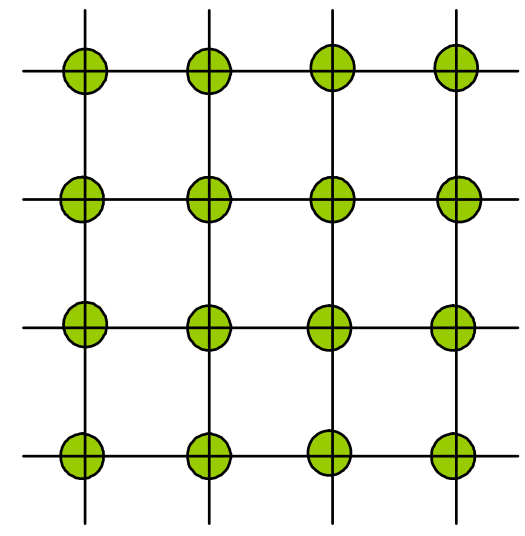

Fig. 6: Deployment scenario $1-4 \times 4$ array of sonobuoys

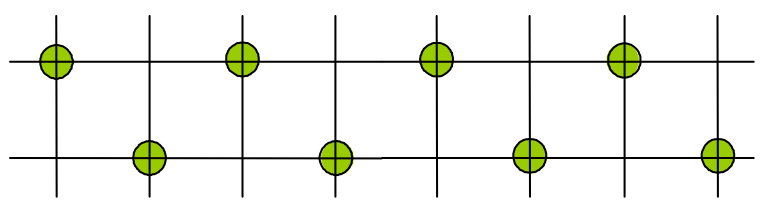

Fig. 7: Deployment scenario $2-4 \times 2$ array of sonobuoys

In order to examine the effectiveness of the ANFIS module in providing reliable prediction of the target range, we added uncertainties to the simulated data.The range determined when the target was detected with one Sonobuoy was simulated with relatively high level of uncertainty $(0.8 \mathrm{Nm})$ while the range determined when the target was detected with two sonobuoys was simulated with lower level of uncertainty equivalent to $0.1 \mathrm{Nm}$. The unit $\mathrm{Nm}$ corresponds to Nautical Mile, which is equivalent to $1852 \mathrm{~m}$.

For each of the above cases, we first studied the performance for the whole trajectory considering: (1) Only one sonobuoy detecting the target; (2) Two sonobuoys detecting the target. We compare the result of each of these two situations with respect to the true trajectory. This is followed by introducing several periods along the same trajectory during which the target was only detected by one sonobuoy and we examine the performance of the ANFIS module in providing reliable prediction of the target position. The assumption of having the position obtained from 2 sonobuoys available for the whole trajectory is just to be used for examining the accuracy of the ANFIS prediction. In general, once the ANFIS module was first generated and updated within one scenario, it can be further utilized in different scenarios involving different array of GPS sonobuoys even if there is only one sonobuoy detecting the target. 


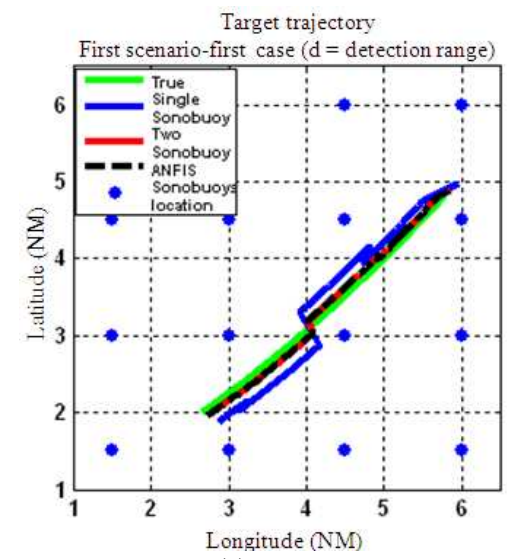

(a)

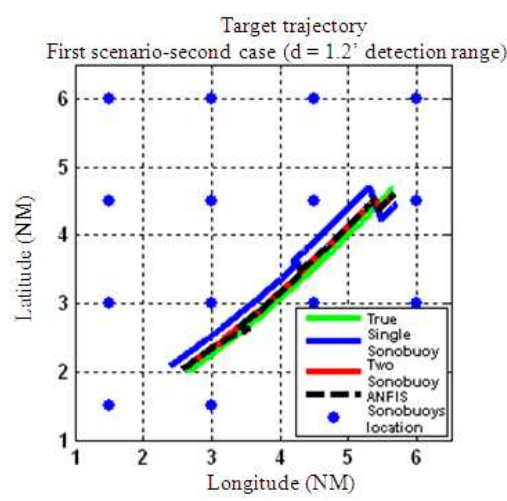

(b)

Fig. 8: Target trajectory-scenario 1. (a): Case 1 (b): Case 2

Figure 8 shows the trajectory of the target for each cases of scenario 1 of sonobuoy deployment (shown earlier in Fig. 6). In Fig. 8a, we were assuming that the target was moving within the detection range of at least two sonobuoys in order to examine its benefits over the case of single sonobuoy detection, while in Fig. $8 \mathrm{~b}$ the target was moving within 1.2 the detection range of the sonobuoy. It can be shown from Fig. 8a and b that the corrected positioning by one sonobuoy is completely following the positioning by two sonobuoys over the entire experiment with the error in between evaluated to have RMSE value of $0.004 \mathrm{Nm}$ for case 1 and 0.008 for case 2. This is due to the fact that once the target is moving within a range higher than the detection range for sonobuoy several disturbances and different trends during motion could be occurred and experienced. In fact, the proposed ANFIS module was able to prevent the error growth of positioning the range based on single sonobuoy that reached $200 \mathrm{Nm}$ errors while operating without update in case single sonobuoy was detecting the target.

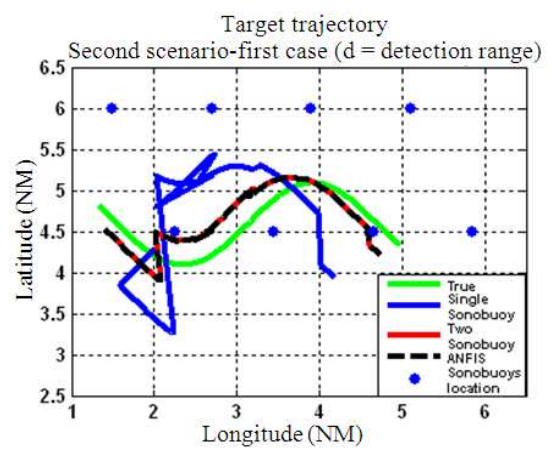

(a)

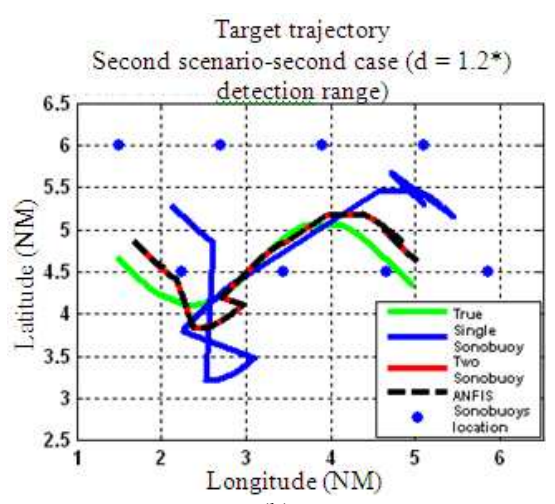

(b)

Fig. 9: Target trajectory-scenario 2. (a): Case 1 (b): Case 2

Moreover, the proposed ANFIS module was examined over the scenario 2 for both cases of target moving. Figure $9 \mathrm{a}$ and $\mathrm{b}$ shows the model performance during the update mode. It can be observed that although the target detection by single sonobuoy was more erroneous than the first scenario, the model was capable of providing the same performance for both cases of detection ranges.

In general, as long as the target is within the detection range of two or more sonobuoys, the ANFIS update procedure tunes the parameters of the ANFIS module in order to mimic the latest dynamics of the target. Once the target falls within the detection range of only one sonobuoy, the ANFIS module uses the latest updated parameters and operates in the prediction mode. For each of the scenarios and the cases simulated in this study, we intentionally introduced several regions within each trajectory during which only one sonobuoy is detecting the target. This way we were able to examine the ANFIS prediction capabilities. Figure 10-13 shows the performance of the proposed system during periods of single sonobuoy detection. 
Target localization

"First scenario- second case ( $\mathrm{d}=$ detection range)"

ANFIS behavior in absence of high accuracy measurements

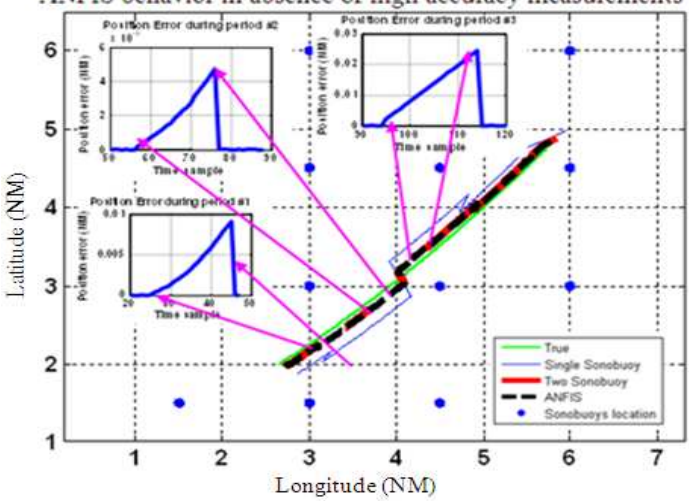

Fig. 10: ANFIS prediction capability during periods of single sonobuoy detection-scenario 1 -case 1

Target localization

"Second scenario- second case ( $\mathrm{d}=1.2$ " detection range)" ANFIS behavior in absence of high accuracy measurements

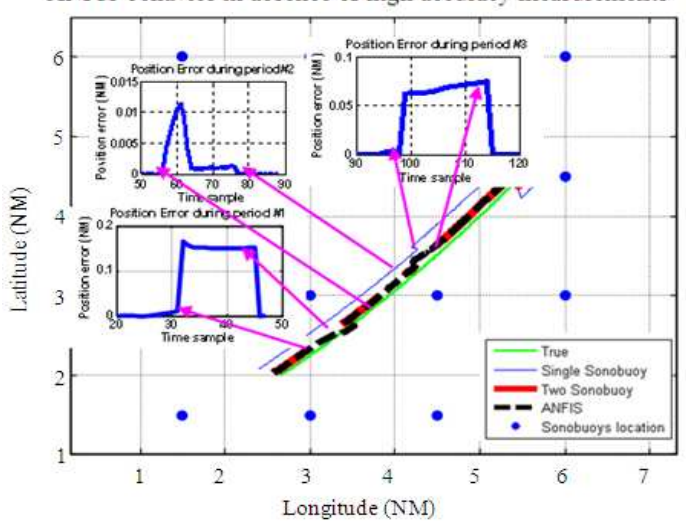

Fig. 11: ANFIS prediction capability during periods of single sonobuoy detection-scenario 1 -case 2

It can be depicted that, in general, the ANFIS module was able to maintain the target tracking accuracy during periods of single sonobuoy detection to that when the target falling in the detection age of two sonobuoys. In other words, the proposed method provides consistent underwater target tracking accuracy regardless of the number of sonobuoys detecting the target.

In fact, for scenario 1 (Fig. 10), we have determined that the ANFIS-based data fusion module was able to predict the target position with errors ranging between $0.004 \mathrm{Nm} 0$ and $0.02 \mathrm{Nm}$ while the distance between the sonobuoys equivalent to the detection range. This accuracy level was reduced when the distance between the sonobuoys became $20 \%$ larger (1.2 the detection range) where the ANFIS-based module gave errors of 0.01-0.1 Nm as can be shown in Fig. 11 .
Target localization

"Second scenario - first case ( $\mathrm{d}=$ detection range)"

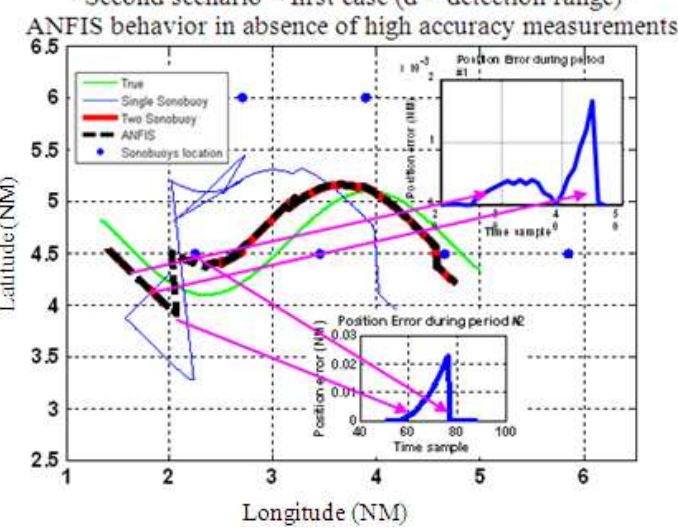

Fig. 12: ANFIS prediction capability during periods of single sonobuoy detection -scenario 2-case 1

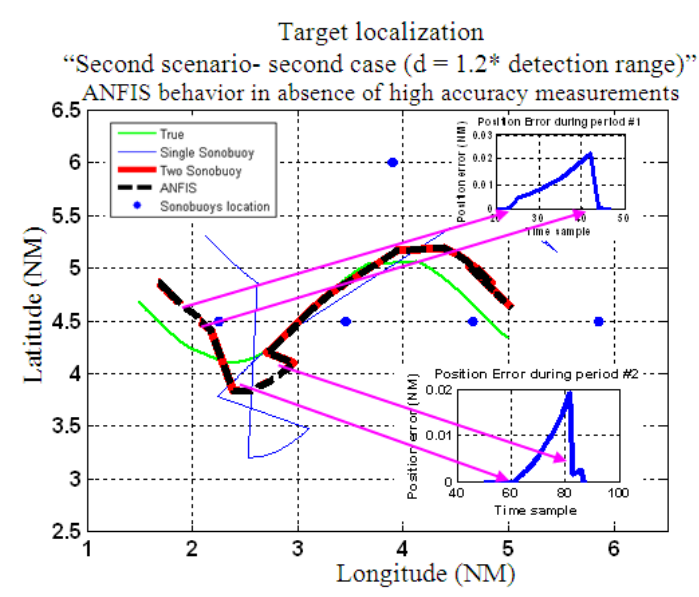

Fig. 13: ANFIS prediction capability during periods of single sonobuoy detection -scenario 2-case 2

For scenario 2 (Fig. 12 and 13), the same accuracy level of approximately $0.02 \mathrm{Nm}$ can be noticed in the two cases of different distances between the sonobuoys. The main reason of this is the complexity in tracking the target while the sonobuoys are deployed in $4 \times 2$ array.

\section{DISCUSSION}

The ANFIS-based module suggested in this study solved a major problem in underwater target tracking where the target falls in the detection range of only one Sonobuoy. This results in large localization errors and jeopardizes the overall system accuracy especially in cases of maneuvering target and low SNR. The proposed module was able to benefit from the capability 
of ANFIS in establishing an empirical model of the range errors in challenging underwater environments. Real time operation of the suggested module was also approached in this study by introducing windowing training approaches. As results indicated, the overall system performance can be greatly enhanced and the tracking accuracy can be improved.

\section{CONCLUSION}

This study suggests the use of ANFIS based data fusion module for real-time integration of array of GPS sonobuoys encompassing two main features. The first is employing real-time cross-validation during the update stage, when the targets falls within the detection range of more than 2 GPS sonobuoys. The second feature is the utilization of non-overlapping moving window technique instead of sliding window technique. The proposed module was examined with realistic simulation data of two scenarios and with considering two cases of different distance between the sonobuoys. Results showed that the proposed ANFIS module could significantly improve target tracking accuracy in cases of single sonobuoy detection, thus maintaining consistent levels of accuracy over the whole tracking mission.

\section{ACKNOWLEDGMENT}

This research is funded in part by (1): The Department of National Defense through the Aerospace Engineering Research Advisory Committee and by the Natural Science and Engineering Research CouncilNSERC for second and third researchers (2): The Smart Engineering System, University Kebangsaan Malaysia, Malaysia.

\section{REFERENCES}

1. Burdic, W.S., 1984. Underwater Acoustic System Analysis. 2nd Edn., Prentice Hall, Englewood Cliffs, New Jersey, USA., ISBN: 0139367160, pp: 445.

2. Korenberg, M.J., 1989. A robust orthogonal algorithm for system identification and time-series analysis. Biol. Cybernet., 60: 267-276. DOI: 10.1007/BF00204124

3. Whitehouse, H.J., J.M. Alsupa, A. Leese de Escobar and S.F. Sullivan, 2004. A GPS sonobuoy localization system. Proceeding of the IEEE Symposium on Position Location and Navigation, April 26-29, IEEE Xplore, USA., pp: 414-417. http://ieeexplore.ieee.org/ielx5/9147/29049/013090 24.pdf?tp=

4. Karim, S., M. Mohsen and B. Mohammadreza, 2008. Centralized and decentralized process and sensor fault monitoring using data fusion based on adaptive extended Kalman filter algorithm. Measur. J. Int. Measure. Confederat., 41: 1059-1076. DOI: 10.1016/J.MEASUREMENT.2008.02.009

5. Ross, T.J., 2004. Fuzzy Logic with Engineering Applications. 2nd Edn., John Wiley and Sons Ltd., West Sussex, England, ISBN: 10: 0470860758, pp: 650.

6. Roger Jang, J.S., 1993. ANFIS: Adaptive-networkbased fuzzy inference system. IEEE Trans. Syst. Man Cybernet., 23: 665-685. http://ieeexplore.ieee.org/search/wrapper.jsp?arnu mber $=256541$

7. Prabir, B., C. Edmond and N. Deborah, 1994. A cross-validatory method for dependent data. Biometrika, 81: 351-358. DOI: 10.1093/biomet/81.2.351 